\title{
Left Ventricular Apical Rupture Caused by Takotsubo Cardiomyopathy -Comprehensive Pathological Heart Investigation
}

\author{
Jerzy Sacha, MD; Jacek Masełko*; Andrzej Wester; \\ Zbigniew Szudrowicz, MD*; Władysław Pluta, MD
}

\begin{abstract}
An 81-year-old woman with emotionally-induced takotsubo cardiomyopathy developed a fatal left ventricular (LV) apical rupture. During the hospitalization persistent ST-segment elevation with no electrocardiographic time evolution was observed on the ECG, characteristic for takotsubo cardiomyopathy. Histopathologically, transmural myocardial necrosis with hemorrhage was found at the rupture site, but there were foci of coagulation and contraction band necrosis with mononuclear lymphocyte infiltrations in other heart regions, and the intensity and distribution of these pathological changes corresponded to the distribution of the LV contraction abnormalities seen on ventriculography. The article concludes that: the LV functional disorder in takotsubo cardiomyopathy may be caused by distracted foci of coagulation and contraction band necrosis in the myocardium; contraction band necrosis (a sign of catecholamine cardiotoxicity) may reflect the sympathetic hyperactivity in this disease; persistent myocardial damage expressed by persistent ST-segment elevation without an electrocardiographic time evolution should be carefully observed with sequential echocardiographic examinations because of the possibility of cardiac rupture. (Circ J 2007; 71: 982-985)
\end{abstract}

Key Words: Catecholamine cardiotoxicity; Contraction band necrosis; Takotsubo cardiomyopathy

$\mathbf{T}$ akotsubo cardiomyopathy is a novel heart syndrome characterized by a transient left ventricular (LV) dysfunction with chest pain, ECG changes and not a high increase in cardiac enzymes, mimicking an acute myocardial infarction!,2 Because of the specific abnormalities of the LV contraction (ie, preserved basal function with apical akinesis or dyskinesis) the disease is also called as 'transient left ventricular apical ballooning' or 'ampulla cardiomyopathy'?,3 The general prognosis is considered to be rather favorable, ${ }^{2-6}$ although some investigators have reported cases with various complications including death?-9 We present a case of takotsubo cardiomyopathy in a female patient who suffered a fatal LV free wall rupture and the results of a comprehensive histopathologic investigation.

\section{Case Report}

An 81-year-old woman with hypertension started to feel chest pains after a quarrel with her son. Next day stomach pains and diarrhea appeared but the chest pain became intermittent, and the symptoms were accompanied by general fatigue. On the third day she was admitted to hospital because of chest discomfort at rest and ECG signs of ST-segment elevation myocardial infarction (MI) (Fig 1A). She had no history of prior angina or MI and no family history of heart disease and sudden death. On admission her heart rate was 104 beats/min, and blood pressure was

(Received September 11, 2006; revised manuscript received March 6, 2007; accepted March 19, 2007)

Departments of Cardiology, *Pathology, Regional Medical Center in Opole, Opole, Poland

Mailing address: Jerzy Sacha, MD, Department of Cardiology, Regional Medical Center in Opole, Al. Witosa 26, 45-418 Opole, Poland. E-mail: sacha@op.pl
$150 / 90 \mathrm{mmHg}$. Auscultation of the heart and lungs was normal, abdominal and neurological examination findings were negative, and there was no peripheral edema. Immediate coronary angiography did not reveal any significant coronary artery stenosis (Figs 2A,B); the TIMI frame counts for the left anterior descending, circumflex and right coronary arteries were 29, 20 and 26 frames, respectively. However, ventriculography revealed a balloon-like LV motion abnormality with akinesis from the mid to apical portions and hyperkinesis of the base (Figs 2C,D). The LV end-systolic and end-diastolic pressureas were $150 \mathrm{mmHg}$ and $15 \mathrm{mmHg}$, respectively, and there was no pressure gradient from the apex and midportion to the outflow tract; other hemodynamic data and the laboratory data on admission are shown in Table. After angiography the patient reported pain relief and was taken to the intensive care unit; however, the ECG recording showed no restoration of normal ST-segment (Fig 1B). The woman was stable during the first $40 \mathrm{~h}$ of admission, with no hemodynamic or arrhythmic problems, and she was given $\beta$-blocker (metoprolol), angiotensin-converting enzyme inhibitor (ramipril) and aspirin; her blood pressure was within normal limits. She occasionally complained of chest discomfort; her creatine kinase-MB was maximal on admission and gradually diminished in further examinations, but the ST segment remained elevated (Figs 1C,D). After $40 \mathrm{~h}$ of admission she reported a sudden pain in the epigastric region and the symptoms of acute abdomen soon appeared (C-reactive protein reached $267 \mathrm{mg} / \mathrm{dl}$ ). After surgical consultation the woman was taken to the operation room for urgent surgery where she suddenly lost consciousness, her blood pressure collapsed, followed by electromechanical dissociation. Resuscitation did not restore circulation and the patient died $44 \mathrm{~h}$ after admission. 


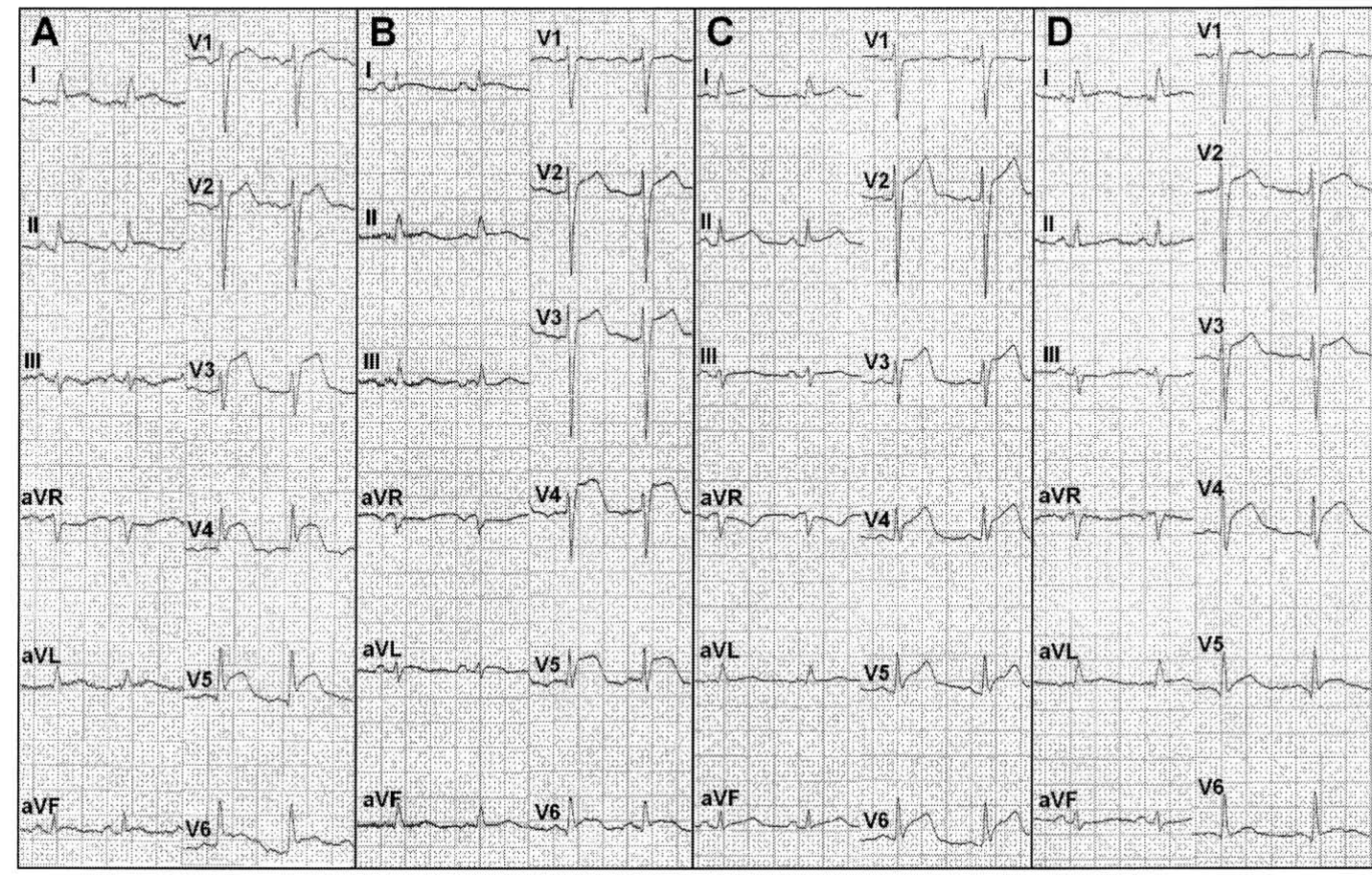

Fig 1. ECG recordings. (A) On admission; (B) after coronary angiography; (C) after $15 \mathrm{~h}$ of hospitalization; (D) after 40 $\mathrm{h}$ of hospitalization. Diffuse ST-segment elevation in the precordial and limb leads can be seen on all recordings. No ECG time evolution (ie, ST-segment restoration, T-wave inversion and QTc interval prolongation) can be seen.

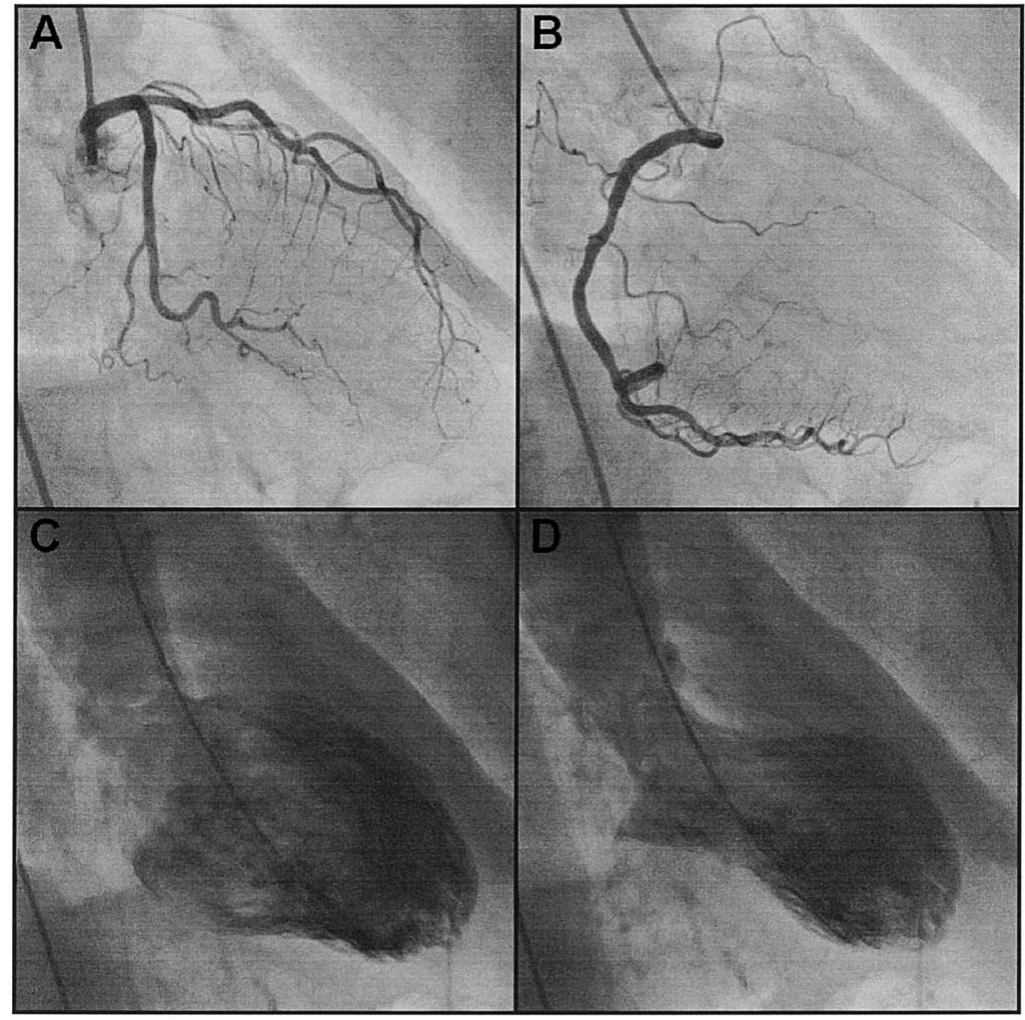

Fig 2. Coronary angiography and ventriculography performed in the 30-degree right anterior oblique projection. (A) Left coronary artery; (B) right coronary artery; (C) end-diastolic ventriculography; (D) end-systolic ventriculography. No significant coronary artery stenosis can be found, but ventriculography reveals balloon-like left ventricular motion abnormality with akinesis from the mid to apical portions and hyperkinesis of the base.

\section{Pathological Investigation}

The autopsy revealed hemopericardium with a LV free wall rupture measuring $10 \mathrm{~mm}$ in the apical region, and no obstructive lesions in the coronary arteries. Inside the heart, there was a mural thrombus in the apical area. Additionally, there were signs of peripheral mesenteric embolism with corresponding necrotic changes in the bowel (measuring $7 \mathrm{~cm}$ ).

Microscopic examination revealed transmural myocardial necrosis with hemorrhage and mild focal polymorphonuclear leukocyte infiltration at the rupture site. In the 
Table 1 Hemodynamic and Laboratory Data on Admission

\begin{tabular}{|c|c|}
\hline \multicolumn{2}{|l|}{ Hemodynamic data } \\
\hline Ejection fraction & $40.6 \%$ \\
\hline End-diastolic volume & $74.8 \mathrm{ml}$ \\
\hline End-systolic volume & $44.4 \mathrm{ml}$ \\
\hline Stroke volume & $30.4 \mathrm{ml}$ \\
\hline End-diastolic volume index & $46.1 \mathrm{ml} / \mathrm{m}^{2}$ \\
\hline End-systolic volume index & $27.4 \mathrm{ml} / \mathrm{m}^{2}$ \\
\hline Stroke volume index & $18.7 \mathrm{ml} / \mathrm{m}^{2}$ \\
\hline \multicolumn{2}{|l|}{ Laboratory data } \\
\hline White blood cell count & $21.6 \times 10^{3} \not \mu l$ \\
\hline Red blood cell count & $5.49 \times 10^{6} \not \mu l$ \\
\hline Hemoglobin & $15.3 \mathrm{~g} / \mathrm{dl}$ \\
\hline Hematocrit & $45.4 \%$ \\
\hline Platelet count & 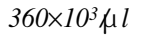 \\
\hline Urea nitrogen & $53.9 \mathrm{mg} / \mathrm{dl}$ \\
\hline Creatinine & $0.84 \mathrm{mg} / \mathrm{dl}$ \\
\hline Sodium & $140 \mathrm{~mol} / \mathrm{L}$ \\
\hline Potassium & $4.0 \mathrm{~mol} / \mathrm{L}$ \\
\hline Glucose & $156 \mathrm{mg} / \mathrm{dl}$ \\
\hline Creatine kinase- $M B$ & $22 U / L$ \\
\hline Troponin $T$ & $1.55 \mu \mathrm{g} / \mathrm{L}$ \\
\hline Aspartate aminotransferase ( $s G O T)$ & $27 U / L$ \\
\hline Alanine aminotransferase (sGPT) & $18 U / L$ \\
\hline$C$-reactive protein & $10.5 \mathrm{mg} / \mathrm{dl}$ \\
\hline Prothrombin time & $11.7 \mathrm{~s}$ \\
\hline International normalized ratio & 0.99 \\
\hline Activated partial thromboplastin time & $26.5 s$ \\
\hline
\end{tabular}

apex (especially around the rupture), multiple fused foci of coagulation necrosis in various phase of myodestruction and contraction band necrosis were found (Fig 3). These changes were not homogeneous, but consisted of multiple merged smaller foci and were accompanied by mononuclear lymphocyte infiltrations. In the midportion of the left ventricle, the foci were less frequent and only occasionally merged together; similar, single sites without merging were also found in the basal portion. There was no necrosis in the specimens coming from the right ventricle, in which there was only slight myocardial fibrosis.

\section{Discussion}

In most of the reported cases takotsubo cardiomyopathy has been associated with a very good prognosis (ie, symptoms and LV dysfunction disappear in a relatively short time) ${ }^{2-6}$ Only a few investigators have described complications, usually heart failure, thrombus and arrhythmia9, but mechanical complications (such as cardiac rupture) are extremely rare?,8 The cause of this disease, as well as the cause of the peculiar LV disorder, are unknown.

In the present case, an 81-year-old woman suffering from takotsubo cardiomyopathy died from a LV rupture. The unique observation in this case is that the LV functional abnormalities seen on ventriculography corresponded to the distribution and intensity of the coagulation and contraction band necrosis: most of the multiple foci of these changes were found in the apex, less frequently in the midportion and only occasionally in the basal portion, and they were accompanied by mononuclear lymphocyte infiltrations. This histopathologic picture is distinct from the diffuse myocardial necrosis with extensive polymorphonuclear infiltration usually seen around a rupture associated with MI10

To the best of our knowledge this is the second autopsy case of takotsubo cardiomyopathy; the first was reported by Ohara et $\mathrm{al}^{8}$ who investigated a patient with LV free wall rupture and reported inflammatory infiltrates and myocytes

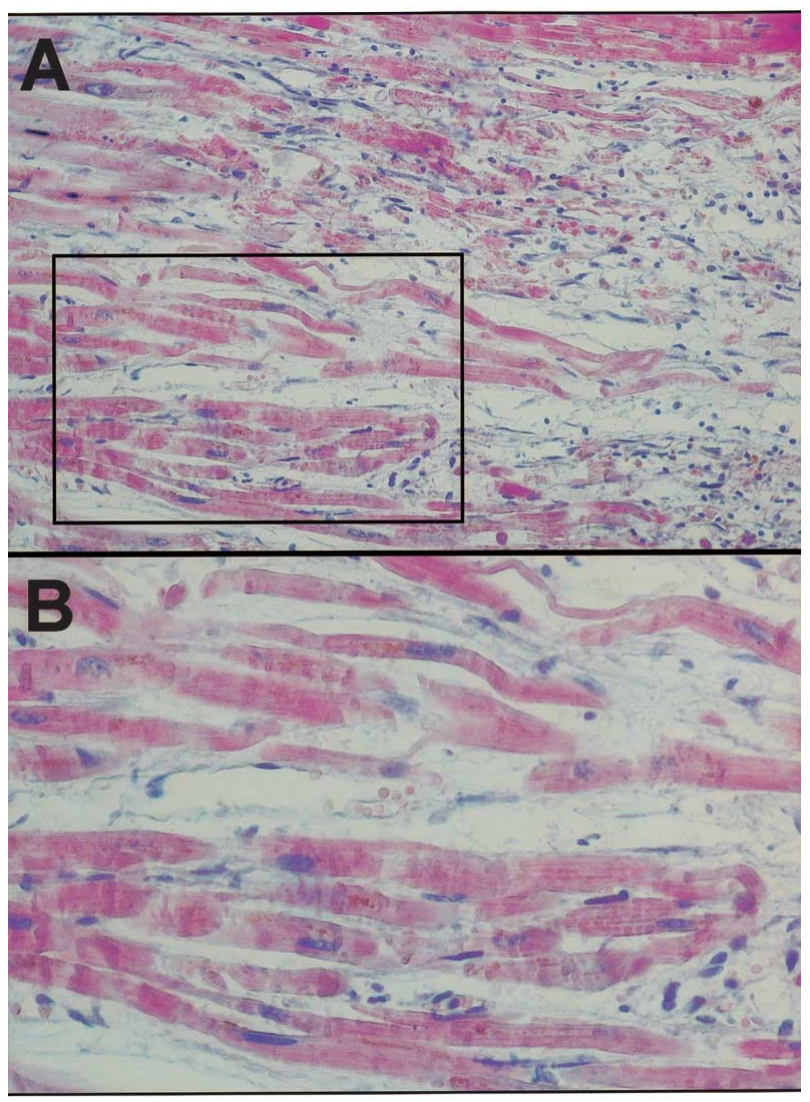

Fig 3. Histopathological findings. (A) Specimen from the area around the rupture shows coagulation necrosis in various phases of myodestruction and contraction band necrosis with mononuclear lymphocyte infiltrations ( $\times 200)$. (B) Enlargement of inset in (A) more clearly shows the contraction band necrosis and myofibrillar disruption (hematoxylin-eosin).

necrosis only at the site of rupture, but, unlike our case, they did not report contraction band necrosis or any pathological changes in other regions of the heart. Wittstein et al performed endomyocardial byopsy in several patients with takotsubo cardiomyopathy and found multiple foci of contraction band myocyte necrosis and lymphocytic infiltrates.

Contraction band necrosis is typical of catecholamine cardiotoxicity ${ }^{10,11}$ which is a form of myocyte injury that has been described in many clinical situations with catecholamine excess (eg, pheochromocytoma or subarachnoid hemorrhage) $!^{2,13}$ It has also been found in people who died in tragic circumstances! ${ }^{14}$ Many researchers suggest that the huge sympathetic stimulation from emotional or physical stress plays a primary role in takotsubo cardiomyopathy, which is reflected in the high increase in the catecholamine plasma level in these patients?,4-6 However, it is unclear why the apex of the heart is usually affected and the basal segments are spared. One possible explanation is the different distribution of sympathetic nerves and the density of receptors in the LV myocardium (ie, being high in basal segments and low in the apex for the nerves, and low in basal segments and high in the apex for the receptors) $)^{15,16}$ We speculate that the distribution of sympathetic receptors corresponds to the distribution of the pathological changes in the present patient, which in turn corresponds to contraction abnormalities of the left ventricle. In an animal study, a 180-min electrical stimulation of a unilateral dorsal medulla 
in vagotomized cats caused significant dilatation of the left ventricle, especially in the apex, and additionally cardiac pathology revealed contraction band necrosis, myocardial hemorrhage and cardiomyocyte apoptosis ${ }^{17}$ That animal model of sympathetic hyperexcitation corresponds very well to both the functional and pathological features of takotsubo cardiomyopathy in humans. Nevertheless, we did not measure the patient's cathecholamine level, so it is hard to conclude that sympathetic hyperactivity and catecholamine excess caused the cardiac damage in the present case.

Several reports support the concept of a functional coronary circulation disorder in takotsubo cardiomyopathy; both epicardial coronary arterial spasm and microvascular spasm are observed in the acute phase $3,6,16$ In the present patient we did not see any spontaneous coronary spasm, and the TIMI frame counts were within normal limits for all coronary arteries, despite the fact that the ST segment was still elevated. However, we can not definitely exclude coronary microvascular dysfunction.

The most important issue is how to predict cardiac rupture in usually benign takotsubo cardiomyopathy. In our opinion, the only symptoms that could reflect continuously occurring damage of the heart were the persistent STsegment elevation on ECG throughout the whole hospitalization (Fig 1) and the high level of C-reactive protein on the day of the rupture. Kurisu et al ${ }^{18}$ reported that the ST segment usually returns to normal within 3 days of the onset of the disease and the $\mathrm{T}$ wave becomes inverted within 2 days, then becomes shallow for several days and deepens again at approximately $2-3$ weeks. The QTc interval prolongs as the $\mathrm{T}$ wave deepens, and shortens as the $\mathrm{T}$ wave becomes shallow. If we assume the disease started 3 days before admission of the present patient, and we know the hospitalization lasted almost 2 days, we may conclude that after 5 days there was no ECG evolution in this patient. The persistent ST-segment elevation as a sign of continuing myocardial damage and possible cardiac rupture was also postulated by Ohara et al in their report of a similar complication in takotsubo cardiomyopathy? As regards the C-reactive protein level, it is hard to interpret its high level only as a consequence of myocardial damage because the patient also suffered from acute abdomen (caused by mesenteric embolism); nevertheless, the heart pathology, at least in part, augmented the level of this protein. Finally, we cannot exclude the possibility that additional stress (ie, the symptoms of acute abdomen) aggravated the takotsubo cardiomyopathy and resulted in cardiac rupture.

It is also important to recognize that takotsubo-like LV dysfunction can induce thrombosis? Mesenteric embolism occurred in the present case and we found a mural thrombus in the left ventricle. Thus, cardiac catheterization must be performed with caution, and adequate antithrombotic treatment is required to prevent systemic embolism.

In conclusion, (1) the LV functional abnormalities in the present case corresponded to the distribution and intensity of coagulation and contraction band necrosis in the myocardium and thus these pathological changes my be a cause of the contraction disorder in takotsubo cardiomyopathy; (2) contraction band necrosis is typical for catecholamine cardiotoxicity and may reflect sympathetic hyperactivity in this cardiomyopathy; and (3) the persistent myocardial damage expressed by persistent ST-segment elevation without typical electrocardiographic time evolution (for more than 3 days), especially associated with a high C-reactive protein level, should be carefully observed with sequential echocardiographic examinations because of the probable continuing myocardial damage and possible cardiac rupture.

\section{Acknowledgment}

We thank Paul McKeown for his assistance with the manuscript.

\section{References}

1. Dote K, Sato H, Tateishi H, Uchida T, Ishihara M. Myocardial stunning due to simultaneous multivessel coronary spasms: A review of 5 cases. J Cardiol 1991; 21: 203-214.

2. Tsuchihashi K, Ueshima K, Uchida T, Oh-mura N, Kimura K, Owa $\mathrm{M}$, et al; Angina Pectoris-Myocardial Infarction Investigations in Japan. Transient left ventricular apical ballooning without coronary artery stenosis: A novel heart syndrome mimicking acute myocardial infarction: Angina Pectoris-Myocardial Infarction Investigations in Japan. J Am Coll Cardiol 2001; 38: 11-18.

3. Kawai S, Suzuki H, Yamaguchi H, Tanaka K, Sawada H, Aizawa T, et al. Ampulla cardiomyopathy ('Takotusbo' cardiomyopathy)reversible left ventricular dysfunction: With ST segment elevation. Jpn Circ J 2000; 64: 156-159.

4. Wittstein IS, Thiemann DR, Lima JA, Baughman KL, Schulman SP, Gerstenblith G, et al. Neurohumoral features of myocardial stunning due to sudden emotional stress. N Engl J Med 2005; 352: 539-548.

5. Ishikawa K. "Takotsubo" cardiomyopathy: A syndrome characterized by transient left ventricular apical ballooning that mimics the shape of a bottle used for trapping octopus in Japan. Intern Med 2004; 43: $275-276$.

6. Kurisu S, Sato H, Kawagoe T, Ishihara M, Shimatani Y, Nishioka K, et al. Tako-tsubo-like left ventricular dysfunction with ST-segment elevation: A novel cardiac syndrome mimicking acute myocardial infarction. Am Heart J 2002; 143: 448-455.

7. Akashi YJ, Tejima T, Sakurada H, Matsuda H, Suzuki K, Kawasaki $\mathrm{K}$, et al. Left ventricular rupture associated with Takotsubo cardiomyopathy. Mayo Clin Proc 2004; 79: 821-824.

8. Ohara Y, Hiasa Y, Hosokawa S, Tomokane T, Yamaguchi K, Ogura $\mathrm{R}$, et al. Left ventricular free wall rupture in transient left ventricular apical ballooning. Circ J 2005; 69: 621-623.

9. Donohue D, Movahed MR. Clinical characteristics, demographics and prognosis of transient left ventricular apical ballooning syndrome. Heart Fail Rev 2005; 10: 311-316.

10. Schoen FJ. The heart. In: Cotran RS, Robbins SL, Kumar V, Schoen FJ, editors. Robbins pathologic basis of disease. Philadelphia: WB Saunders; 1994; 517-582.

11. Samuels MA. Neurally induced cardiac damage: Definition of the problem. Neurol Clin 1993; 11: 273-292.

12. Wilkenfeld C, Cohen M, Lansman SL, Courtney M, Dische MR, Pertsemlidis D, et al. Heart transplantation for end-stage cardiomyopathy caused by an occult pheochromocytoma. J Heart Lung Transplant 1992; 11: 363-366.

13. Neil-Dwyer G, Walter P, Cruickshank JM, Doshi B, O'Gorman P. Effect of propranolol and phentolamine on myocardial necrosis after subarachnoid haemorrhage. BMJ 1978; 2: 990-992.

14. Cebelin MS, Hirsch CS. Human stress cardiomyopathy: Myocardial lesions in victims of homicidal assaults without internal injuries. Hum Pathol 1980; 11: 123-132.

15. Murphree SS, Saffitz JE. Quantitative autoradiographic delineation of the distribution of beta-adrenergic receptors in canine and feline left ventricular myocardium. Circ Res 1987; 60: 568-579.

16. Kume T, Akasaka T, Kawamoto T, Yoshitani H, Watanabe N, Neishi $\mathrm{Y}$, et al. Assessment of coronary microcirculation in patients with takotsubo-like left ventricular dysfunction. Circ J 2005; 69: 934-939.

17. Chiu YT, Chen YT, Lin NN, Chenq CC, Gong CL, Chenq FC, et al. Sympathetic activity and myocardial damage after stimulation of dorsal medulla and vagotomy in a novel animal model. Int J Cardiol 2005; 100: $401-407$.

18. Kurisu S, Inoue I, Kawagoe T, Ishihara M, Shimatani Y, Nakamura $\mathrm{S}$, et al. Time course of electrocardiographic changes in patients with tako-tsubo syndrome comparison with acute myocardial infarction with minimal enzymatic release. Circ J 2004; 68: 77-81. 